\title{
Low Dose Failures of Hardened DC-DC Power Converters*
}

\author{
J. Lehman, C. Yui, B. G. Rax, T. F. Miyahira, M. Wiedeman, P. Schrock, G. M. Swift, A. H. Johnston, S. Kayali \\ Jet Propulsion Laboratory \\ California Institute of Technology \\ Pasadena, California
}

\begin{abstract}
Radiation tests of Interpoint DC-DC converters, guaranteed by the manufacturer to $100 \operatorname{krad}(\mathrm{Si})$, showed catastrophic failures at total dose levels as low as $4 \mathrm{krad}(\mathrm{Si})$. Special diagnostic tests showed that failures were caused by an internal CMOS MOSFET driver chip being used in an application that differed from earlier radiation tests of the component. This paper discusses radiation testing, failure modes, and the method used to overcome this problem weeks prior to launch of two space systems.
\end{abstract}

\section{INTRODUCTION}

Box-level total dose testing of a fiber optic gyro at ESA's (European Space Agency) Gammabeam Facility were abruptly terminated at $8 \mathrm{krad}(\mathrm{Si})$ due to catastrophic failure (complete shutdown). This was unexpected because all components within the gyro were supposedly radiation tolerant to far higher total dose levels. Further testing showed that the components responsible for the failure were two DC-DC converters, manufactured by Interpoint, that stopped regulating shortly before shutdown. The $28 \mathrm{~F} / \mathrm{KR}$ series of power converters were designed to be radiation hardened to levels of $100 \mathrm{krad}(\mathrm{Si})$. This paper discusses radiation testing, diagnostic tests, and methods to determine the underlying cause of the unexpected failure at low levels of radiation.

Power converter tests are difficult to interpret because the failure level depends on the conditions used for testing and electrical characterization. The specific load conditions that are applied during irradiation have little effect on converter degradation as long as bias voltages are applied and the converter is operating with a suitable heat sink. However, the voltage and load conditions have a large effect on how one defines failure for these devices when they are tested after irradiation. These converters can be used with input voltages from 16 to 40 volts. The first indication of degradation occurs when the converter can no longer regulate when low input voltages are used in combination with high load conditions. The interplay between loading conditions and the voltage required for failure is potentially confusing, and makes it difficult to compare results from different tests. However, our evaluation of load dependence has shown that the failure level depends only on the total load, not the way that it is distributed between the two outputs on dual versions of the converter. Heating of the converter may also play a role in the failure level and recovery. Finally, the dose rate and type of irradiation (proton versus gamma ray) may also affect results [1].

\section{DEVICE DESCRIPTION}

The $28 \mathrm{~F} / 28 \mathrm{~K}$ devices are dual output DC-DC converters manufactured by Interpoint. They are hybrid devices, and they can be manufactured with different types of internal components. This makes it more difficult to ensure that radiation test data actually applies to the converters that are procured for a specific program. Key design features of these devices are as follows:

- They use a TSC4426 MOSFET driver that had previously been radiation tested as an individual component, but nevertheless is suspected to be the internal component that causes the converters to fail at levels well below the $100 \mathrm{krad}(\mathrm{Si})$ level guaranteed by the manufacturer;

- They use a special hardened optocoupler in order to improve their radiation hardness to proton damage compared to standard (unhardened) devices from the same manufacturer; and

- They use hardened power MOSFETs in the output stage.

The samples were procured from the same lot used by the Genesis and Jason programs and the test conditions used to evaluate them were based on applications in the two spacecraft. The Genesis Program is designed to take samples of particles emitted from the sun, and return the samples to earth after a three-year mission; thus, most of its operation is in free space. The mission of the Jason Program (a joint NASA/CNES mission) is monitoring of ocean and other weather-related parameters. It is an earth-orbiting mission, with an altitude of $1338 \mathrm{~km}$ and $98^{\circ}$ inclination. Most of the total dose on the Jason mission comes from trapped protons.

\section{EXPERIMENTAL DETAILS}

\section{A. Overall Description}

After the initial data was reported by ESA, a series of special tests was done on the converters, including proton testing, collimated X-ray testing of individual components in a working converter module, gamma ray tests at various dose

*The research in this paper was carried out at the Jet Propulsion Laboratory, California Institute of Technology, under contract with the National Aeronautics and Space Administration (NASA). 
rates, and interleaved irradiation and anneal cycles. Total dose irradiations were performed using the JPL cobalt-60 high and low dose rate facilities. The bias conditions during irradiation used a fixed load condition of $87 \%$ of maximum; $1.4 \mathrm{~A}$ load on the positive output and $0.7 \mathrm{~A}$ on the negative output, with an input voltage of $28 \mathrm{~V}$. Input and output voltages and currents were monitored throughout irradiation. Special heat sinks were attached to the modules to reduce heating and $\mathrm{Pb}-\mathrm{Al}$ shields were used to eliminate low-energy scattered gamma rays. Proton testing was done at the University of CaliforniaDavis using the same procedures (except for the $\mathrm{Pb}-\mathrm{Al}$ shield) and comparable dose rates.

Prior to our testing, Interpoint identified the TSC4426 MOSFET as the likely internal component involved in the converter's failure from special probe tests of converters that no longer functioned after radiation testing. Figure 1 shows a photograph of the converter, along with the location of the MOSFET driver chip. Diagnostic tests done at JPL included tests with collimated $10-\mathrm{keV}$ X-rays, which irradiated only the TSC4426 driver within the converter, as well as cobalt-60 tests of individual TSC4426 MOSFET drivers from the same lot used in the converters.

Tests were also done on power converter hybrids to determine how the failure level depended on dose rate, load, and temperature. Annealing experiments were also done on some of the converters.

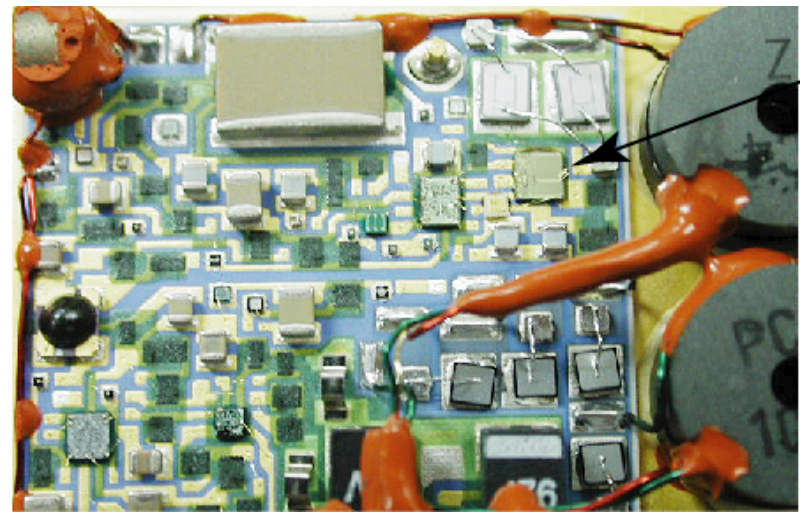

Figure 1: Interpoint DC-DC Power Converter. The arrow points to the location of the MOSFET driver.

\section{B. Electrical Tests}

Two series of electrical tests were performed on the converters before and after irradiation [note that maximum $(100 \%)$ load current is $1.6 \mathrm{~A}]$ :

\section{1) Load Performance with Fixed Input Voltage}

Input voltage was held at each of three voltages $(16,28$, and $40 \mathrm{~V}$ ) while varying the positive load from 10 to $100 \%$ in combination with varying the negative load from 0 to $90 \%$.

\section{2) Input Voltage Ramp Test with Fixed Output Load Conditions}

Load conditions were held at each of three currents $(50 \%$, $75 \%$, and $100 \%$ with a " $2 / 3$ ", " $1 / 3$ " split between the positive and negative outputs) while ramping the input voltage up and down between 16 to $40 \mathrm{~V}$.
The operational requirements of the converter can be understood by examining how the duty cycle of the converter depends on input voltage and load conditions over the specified operating region. Various operating contours are shown in Figure 2. With minimum input voltage and minimum load, the duty cycle of the power MOSFETs in the output stage approaches $50 \%$. As the input voltage increases, the duty cycle required to sustain regulated converter operation decreases, as shown in the figure.

Radiation degradation changes the duty cycle requirements, increasing the minimum voltage required for a given load condition. Note that the first radiation failure is expected at $\mathrm{V}_{\text {in }}=16 \mathrm{~V}$ and $\mathrm{I}_{\text {load }}=0.24 \mathrm{~A}$. Also note there is normally about $2 \mathrm{~V}$ of hysteresis; that is, once the converter is in regulation, it will continue to regulate until the input voltage is about $2 \mathrm{~V}$ lower (when ramping the input voltage down) than at the onset of regulation when ramping the input voltage up[4]. The operating contours in Figure 2 correspond to "ramping up".

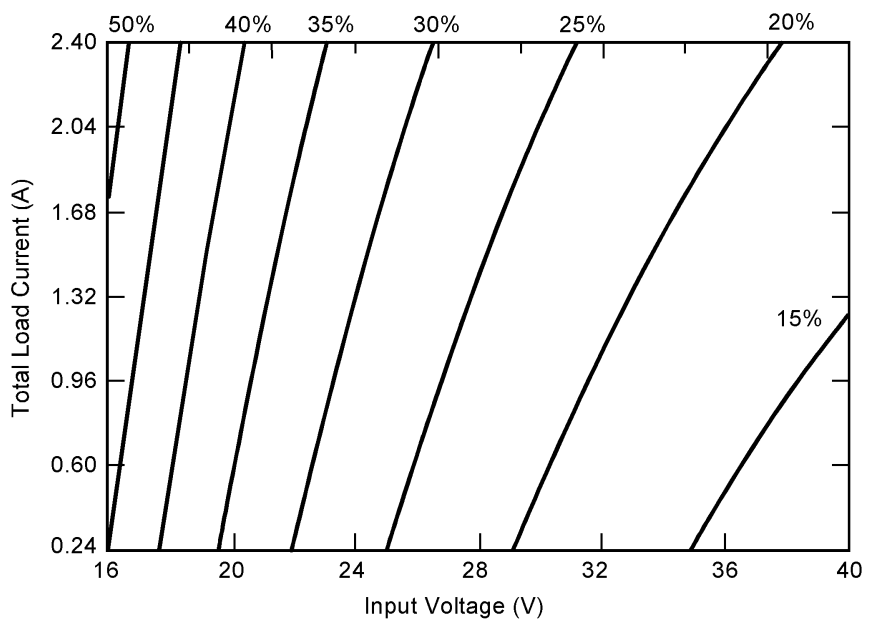

Figure 2: Duty Cycle Contours for the Converters.

Although the onset of degradation can be determined by testing the converter at its specified minimum input voltage and minimum load, applications in the two systems used minimum voltages of 24 to 32 volts. The series of electrical tests that were done after each radiation step determined how the duty cycle contour for each converter degraded after irradiation, allowing one to determine how the converter would perform under different electrical conditions [4].

Some of the converters were subjected to special conditions that varied from test to test in order to determine whether operational changes could compensate for the extreme radiation sensitivity. These included unbiased tests to a certain radiation level, followed by biased tests to higher levels; testing converters containing TSC4426 MOSFET drivers from different lots; testing converters that had been "reworked" by the manufacturer prior to radiation testing, substituting a different MOSFET driver, the TSC4429; and tests with collimated X-rays that could selectively irradiate different internal components within the converter. Annealing 
and supply current tests were also done on several converters after irradiation.

\section{TEST RESUlts}

\section{A. Irradiation of Standard Power Converters}

Eleven standard converters from the same lot were tested, along with several modified converters. The modified units included one with a new lot of the TSC4426 MOSFET driver, two containing unhardened optocouplers, and four where the TSC4426 was replaced with a TSC4429 MOSFET driver (the parts with the TSC4429 had been assembled with soft optocouplers). Results for the eleven standard converters are shown in Table 1. There is some indication that tests at low dose rate increased the radiation failure level slightly (perhaps as much as $20 \%$ ), but the variability between units that were tested under common conditions does not allow any conclusive statement about the effects of dose rate on failure level.

TABLE I. TEST RESUltS FOR THE ELEVEN STANDARD CONVERTERS

\begin{tabular}{|c|c|c|}
\hline$S / N$ & $\begin{array}{l}\text { FAILURE } \\
\text { DOSE } \\
(\text { KRAD(SI)) }\end{array}$ & $\begin{array}{l}\text { DOSE RATE } \\
(\mathrm{RAD}(\mathrm{SI}) / \mathrm{SEC})\end{array}$ \\
\hline 188 & 3.9 & 2.78 \\
\hline 13 & 12 & 2.78 \\
\hline 14 & $\begin{array}{l}5.0 \text { at } 16 \mathrm{~V} \\
5.6 \text { at } 28 \mathrm{~V} \\
6.5 \text { at } 40 \mathrm{~V}\end{array}$ & $\begin{array}{c}2.3 \\
\text { (63-MeV protons) }\end{array}$ \\
\hline 1 & $\begin{array}{l}5.0 \text { at } 16 \mathrm{~V} \\
5.0 \text { at } 28 \mathrm{~V}\end{array}$ & $\begin{array}{c}2.3 \\
\text { (63-MeV protons) }\end{array}$ \\
\hline 23 & 5.0 & 2.78 \\
\hline $9^{*}$ & 5.2 & 2.78 \\
\hline 33 & 9.4 & 2.78 \\
\hline $35^{\star *}$ & 6.3 & 0.0066 \\
\hline $34^{\star *}$ & 8.7 & 0.0066 \\
\hline 10 & $\begin{array}{l}5.0 \text { at } 16 \mathrm{~V} \\
5.4 \text { at } 28 \mathrm{~V} \\
6.2 \text { at } 40 \mathrm{~V}\end{array}$ & 2.78 \\
\hline 31 & $\begin{array}{l}5.9 \text { at } 16 \mathrm{~V} \\
7.3 \text { at } 28 \mathrm{~V} \\
7.7 \text { at } 40 \mathrm{~V}\end{array}$ & 2.78 \\
\hline
\end{tabular}

*Unit 9is an SMHFDF/MR, all others converters are SMHF2805D/KR types. **Devices 34 and 35 were tested at $93 \%$ maximum load instead of an $87 \%$ load.

It was further determined that the low failure levels occurred because the TSC4426 was unable to provide the required pulse duty cycle after ionization damage. Typically the input current of the converter decreased slightly just before the output voltage started to exceed specification limits. Internal probe measurements showed that the output waveform of the MOSFET driver, after irradiation, became severely truncated and failed to follow the input waveform (inputs and outputs are complementary). Figure 3 shows a graphic representation of this truncating.

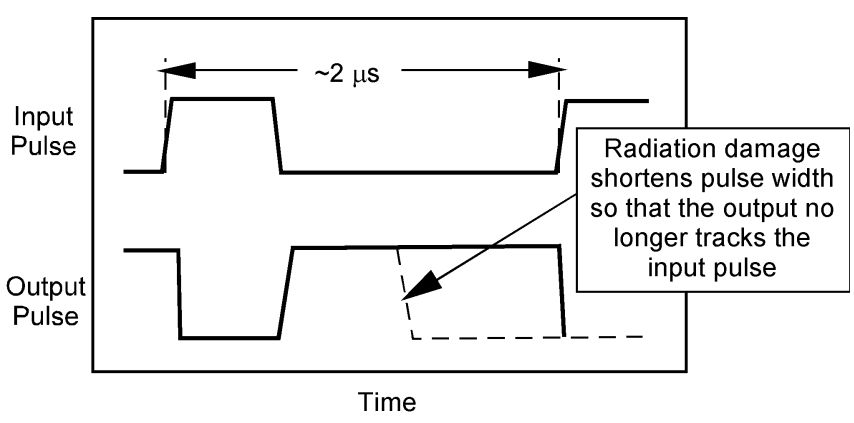

Figure 3: Dynamic failure mode exhibited by the TSC4426 after irradiation.

Figure 4 shows the TSC4426 MOSFET driver internal input and output waveforms of a normal functioning DC-DC Power Converter (top) versus a converter at the onset of failure (bottom). The trailing edge of the output waveform (dotted) becomes truncated and collapses prematurely failing to stay complimentary to the input waveform (solid). At still higher radiation levels only very narrow spikes occur at the output and the converter is completely non-functional.

Under gamma ray irradiation the converter can no longer provide the required output pulse length after a total dose of 4$5 \mathrm{krad}(\mathrm{Si})$, and the maximum pulse length continues to decrease at successively higher total dose levels (Figure 5). Tests of several devices have shown that this behavior occurs between approximately 3.8 and $5.4 \mathrm{krad}(\mathrm{Si})$ for different test samples. For samples tested with $63-\mathrm{MeV}$ protons failure levels are about a factor of two greater than gamma ray results (Figure 6). However, proton test results may be affected by unavoidable differences in the length of time that devices were biased during the tests. Although the same dose rate -- 167 $\operatorname{rad}(\mathrm{Si}) / \mathrm{m}$-- was used for both cobalt-60 and proton tests, it takes more time to turn on the proton test beam and to retrieve the samples after each test run was completed. Thus, samples are biased for a longer time period which may affect the results, particularly after the current increases to approximately $30 \mathrm{~mA}$ when the device is approaching doses where failure occurs. 


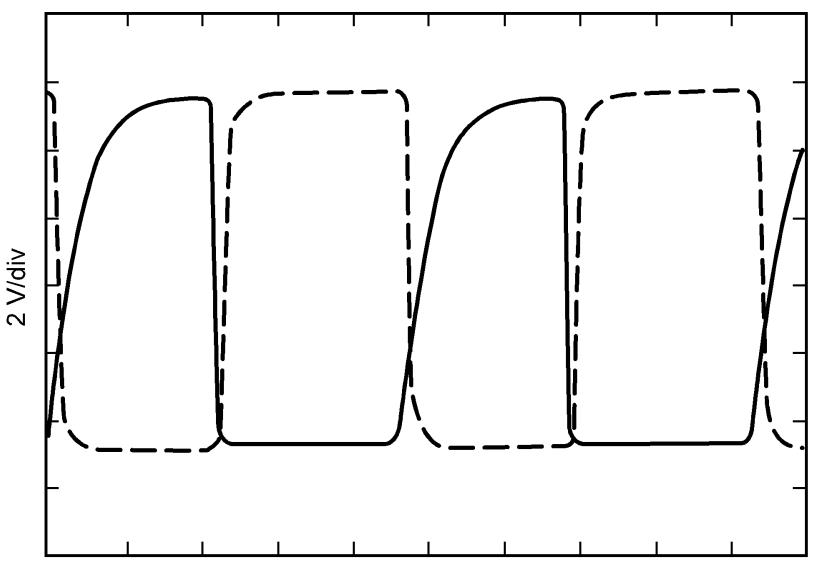

$50 \mathrm{~ns} / \mathrm{div}$

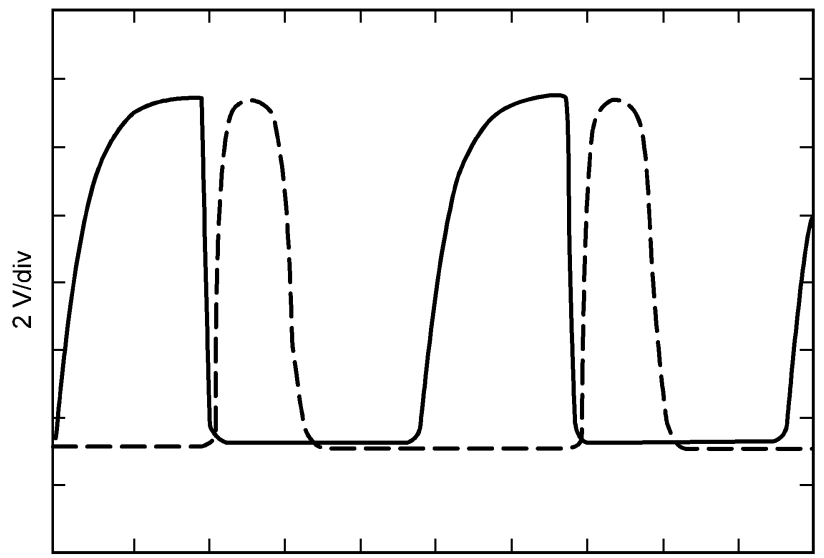

$50 \mathrm{~ns} / \mathrm{div}$

Figure 4: Comparison of Normal Operating DC-DC Power Converter (top) vs. Converter at the Onset of Failure (bottom). (Input 16V, Load 0.24A)

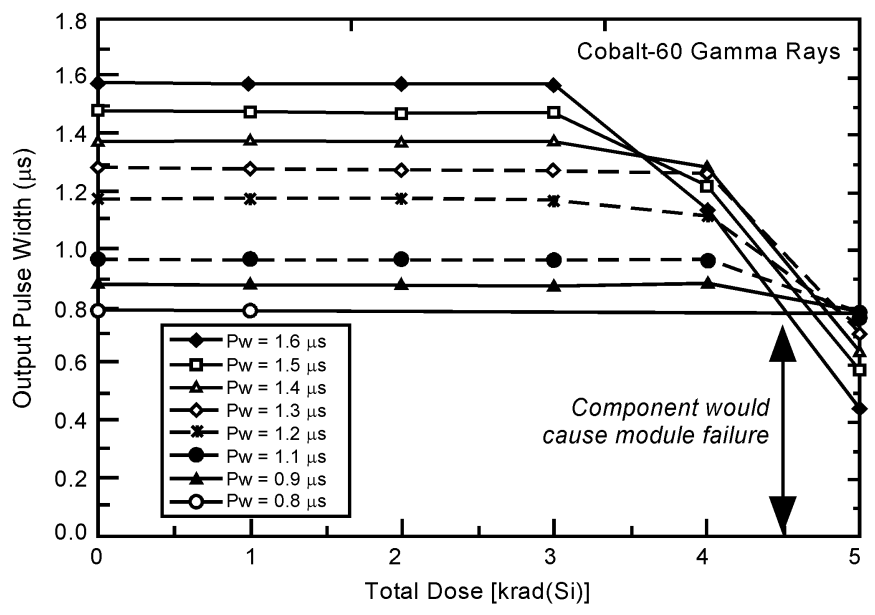

Figure 5: Pulse Width Failure of TSC4426 after Cobalt 60 Gamma Ray Irradiation.

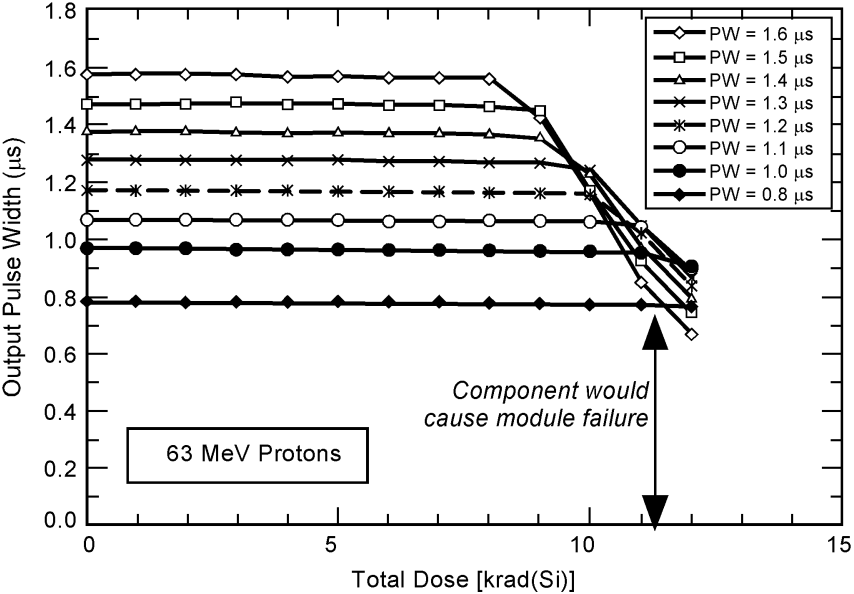

Figure 6: Pulse Width Failure of TSC4426 after $63 \mathrm{MeV}$ Proton Irradiation.

The limited results that are available for annealing show that the converters recover almost completely when the annealing is done at elevated temperature $\left(100{ }^{\circ} \mathrm{C}\right)$, with no bias applied. However, very little annealing appears to take place at temperatures between 35 and $65{ }^{\circ} \mathrm{C}$, which is the expected temperature range in the application. On the one hand, the nearly complete recovery at elevated temperature suggests that annealing under the lower dose rate conditions expected in the application will increase the failure level to much higher levels. On the other hand, because so little annealing takes place at the actual temperatures expected on the spacecraft it is also possible that very little annealing will actually occur. Table 2 shows the annealing conditions along with the incremental total dose required for converter failure when the converters were subjected to an additional irradiation after annealing.

TABLE II. ANNEALING EFFECTS ON DC-DC CONVERTERS

\begin{tabular}{|c|c|c|c|}
\hline $\mathrm{S} / \mathrm{N}$ & $\begin{array}{c}\text { Annealing } \\
\text { Conditions }\end{array}$ & $\begin{array}{c}\text { Hours } \\
\text { Annealed }\end{array}$ & $\begin{array}{c}\text { Post Anneal } \\
\text { Failure Dose } \\
(\mathrm{krad}(\mathrm{Si}))\end{array}$ \\
\hline 13 & $\mathrm{RT}$ & 118 & 2.0 \\
\hline 23 & $60 \mathrm{C}$ & 336 & 6.4 \\
\hline 9 & $60 \mathrm{C}$ & 336 & 7.0 \\
\hline 10 & $100 \mathrm{C}$ & 211 & 5.2 \\
\hline 35 & $\begin{array}{c}65 \mathrm{C} \text { during } \\
\text { irradiation }\end{array}$ & $\mathrm{n} / \mathrm{a}$ & $\mathrm{n} / \mathrm{a}$ \\
\hline 34 & $\begin{array}{c}65 \mathrm{C} \text { during } \\
\text { irradiation }\end{array}$ & $\mathrm{n} / \mathrm{a}$ & $\mathrm{n} / \mathrm{a}$ \\
\hline
\end{tabular}

\section{B. Tests of TSC4426 MOSFET Drivers}

Previous tests of the TSC4426 MOSFET drivers had been done by another laboratory, but those tests used a lower power supply voltage $-5 \mathrm{~V}$ instead of the internal 10.2-11 V within the power converters. The earlier tests also did not include 
timing measurements with the high duty cycle required in the converter application. An additional series of radiation tests were also done on TSC4426 MOSFET driver chips from the same wafer lot used by Interpoint when the converters were manufactured.

There were large increases in power supply current after the TSC4426 failed during dynamic testing and this current was large enough to cause extreme heating of the 4426 once it occurred. Temperature strongly affects gate threshold shifts and field oxide leakage, a possible culprit in the failure mode of the TSC4426 MOSFET drivers. This is not evident under static conditions but has been consistent with all dynamic testing. However, moderate allowances of heating may pose beneficial to prolonging converter failures due to annealing affects. Tests done at higher dose rates with better heat sinks that reduced the converters case temperature to a nominal $35 \mathrm{C}$ generally showed failure levels that were $20-30 \%$ lower than tests done with more limited temperature. Figure 7 shows how the current increases under static and dynamic conditions operating with a repetition rate of $500 \mathrm{kHz}$ (the nominal operating frequency within the Interpoint converter). The static tests done by ICS do not show any large increases in current, which is generally consistent with this result. [1]

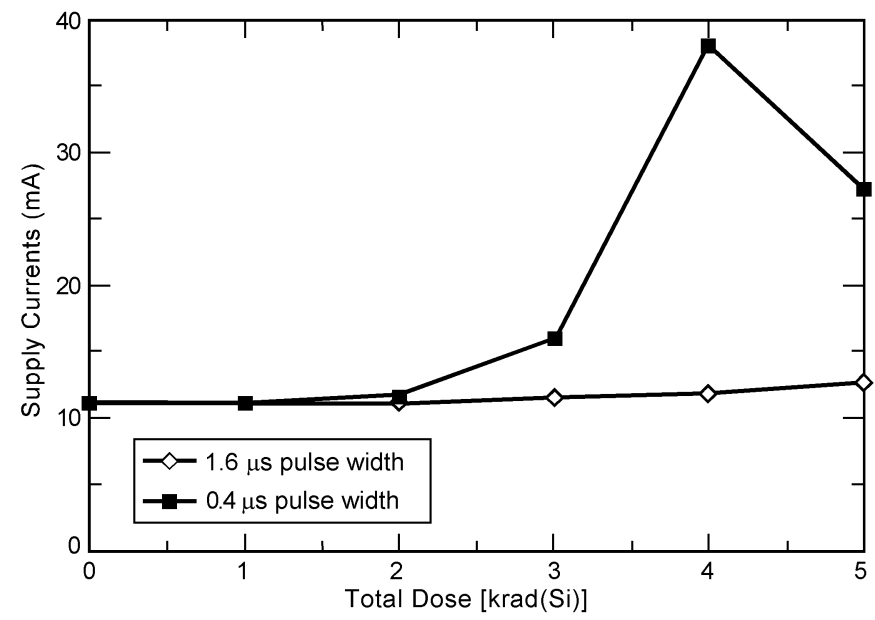

Figure 7: Supply Current versus Total Dose

Unfortunately the test chips are mounted using an epoxy die attach method with much greater thermal resistance compared to devices that are mounted within the Interpoint power converter. Thus, it is quite likely that much less annealing will occur for devices within the converter compared to tests of individual components because the chip temperature will be much lower for devices that are mounted directly to the substrate of the converter.

\section{Reworked Converters}

A MOSFET driver with a slightly different design, the TSC4429 does not exhibit the unusual failure mode of the TSC4426. Additional converters were obtained that used the TSC4429 rather than the TSC4426 (however, they contained unhardened optocouplers). When those converters were tested with gamma ray irradiation they continued to operate over all conditions at levels in excess of $50 \mathrm{krad}(\mathrm{Si})$. However, with proton irradiation, they failed below $10 \mathrm{krad}(\mathrm{Si})$ because of the soft optocoupler. Those results are summarized in Table 3. (No converters were available containing TSC4429 MOSFETs with hard optocouplers.)

TABLE III. DC-DC CONVERTERS CONTAINING TSC4429 REPLACEMENT MOSFET ALONG WITH SOFT OPTOCOUPLER. THE SOFT OPTOCOUPLER CAUSED THE DEVICES TO FAIL AT MUCH LOWER LEVELS WHEN THEY WERE IRRADIATED WITH PROTONS.

\begin{tabular}{|c|c|c|c|}
\hline S/N* & $\begin{array}{c}\text { FAILURE } \\
\text { DOSE } \\
\text { [KRAD(SI)] }\end{array}$ & $\begin{array}{c}\text { DOSE RATE } \\
\text { (RAD(SI)/ } \\
\text { SEC) }\end{array}$ & RADIATION SOURCE \\
\hline 30 & 9.57 & 11 & 63-MeV Protons \\
\hline 32 & $>100$ & 42 & Cobalt 60 gamma ray \\
\hline 38 & 9.47 & 11 & 63-MeV Protons \\
\hline 39 & 53.6 & 50 & Cobalt 60 gamma ray \\
\hline
\end{tabular}

\section{SUMMARY AND CONCLUSIONS}

Several different radiation tests were done on the SMHFseries of Interpoint power converters to determine their failure characteristics, and to verify that the unexpected failures at low total dose levels were really due to radiation damage. For converters that were tested with Cobalt-60 gamma rays using normal heat sinking (an important detail), failures occurred at total dose levels between 3.9 and $12 \mathrm{krad}(\mathrm{Si})$ for several different devices. The mean failure level under these conditions was $6.8 \mathrm{krad}(\mathrm{Si})$. There is some indication that tests at lower dose rates -- $2 \mathrm{rad}(\mathrm{Si}) / \mathrm{m}$ compared to $167 \mathrm{rad}(\mathrm{Si}) / \mathrm{m} \mathrm{-}$ - raises the failure level by about $20 \%$. That is a very small difference considering the amount of time required to irradiate the devices under these conditions. It raises the distinct possibility that these devices may not anneal very much during actual conditions in space.

Proton tests of the entire converter with $63 \mathrm{MeV}$ protons show a mean difference of about $30 \%$ between the mean failure level of converters that were tested with gamma rays. That difference is consistent with the expected difference in charge recombination for thick oxides, such as the field oxide of CMOS devices. However, the median energy of the proton spectrum for the Jason mission, a high-inclination earthorbiting mission at $1338 \mathrm{~km}$, is about $120 \mathrm{MeV}$. Thus, there may be less difference between proton damage in the actual environment than was observed in the laboratory tests at lower proton energy. It is also possible that degradation of other components within the converter may contribute to the failure mechanism. Diagnostic tests with $10-\mathrm{keV} \mathrm{X}$-rays show that degradation of discrete transistors also affect converter operation.

The mean failure level of these converters is more than a factor of two below the required total dose level for five years of operation. Unless additional shielding can be used to reduce the radiation level to about $5 \operatorname{krad}(\mathrm{Si})$, this presents a very high level of risk for the converter in this application. 
It is possible that sufficient annealing will occur in the low dose rates that will actually occur to raise the failure level above the required radiation level. However, the very small differences between failure levels of converters that were irradiated for more than three days ( $2 \mathrm{rad} / \mathrm{min}$ ) compared to converters that were irradiated for less than two hours (167 $\mathrm{rad} / \mathrm{min}$ ) is not encouraging, and suggests that relatively little annealing may actually occur for these devices. This is further borne out by the very small differences in failure level for a converter that was irradiated in steps, with 48 hour annealing periods between successive irradiations, compared to converters that were irradiated without allowing incremental time for annealing. The only way to resolve this is to do irradiations at low dose rate, which will require several months to complete.

Tests of the TSC4426 MOSFET drivers have shown that failure in the converters is the result of a very unusual failure mode in these CMOS devices that cannot be easily explained. This failure mode was not observed when TSC4426s were tested at the component level by a different radiation test laboratory and is only evident when specific tests are done on the TSC4426 devices that replicate the switching and load conditions within the power converters. The failure may be due to either gate threshold shift or field oxide leakage, and is strongly affected by temperature.

Finally, it should be noted that Interpoint was extremely helpful in providing converters for radiation testing, and no longer uses the TSC4426 driver circuits in their converters. The latest versions of their $28 \mathrm{~F} / \mathrm{KR}$ converters do not exhibit the unusual low dose failures that appear to have been caused by a very unusual response mode in the older TSC4426 MOSFET drivers.

\section{REFERENCES:}

[1] Johnston, A. "Radiation Test Results for Interpoint Power Converters." 23 Aug. 2001. (Internal JPL Test Report)

[2] Lehman, J. "Total Dose Radiation Test Report Interpoint SMHF2805."17 Oct 2001. (Internal JPL Report)

[3] McClure, S. "Total Dose Radiation Test Report Interpoint SMTR2805 \& SMTR2815." 17 Oct 2001.

[4] Swift, G.“ Investigations into Early Failures of DC-DC Converters Due to Total Dose." RADECS 2001. 